\title{
Signal-to-Noise Ratios of the Auditory Steady-State Response from Fifty-Five EEG Derivations in Adults
}

\author{
Christoph S. van der Reijden* \\ Lucas H.M. Mens* \\ Ad F.M. Snik*
}

\begin{abstract}
The Auditory Steady-State Response (ASSR) was recorded in 20 awake adults with normal hearing on ten EEG channels simultaneously to find derivations with the best signal-to-noise ratios (SNRs). Stimuli were $20 \%$ frequency modulated tones of 0.5 and $2 \mathrm{kHz}$ at $20 \mathrm{~dB}$ SL, $100 \%$ amplitude modulated at 90 or $94 \mathrm{~Hz}$, and presented one at a time to one ear.
\end{abstract}

ASSR recordings using a set of at least three channels improved SNRs significantly by an average of between $6 \%(500 \mathrm{~Hz}$ right ear) to $118 \%(2 \mathrm{kHz}$ right ear) above the SNRs from the conventional channels. Assuming that the recording time was proportional to $1 /(\mathrm{SNR})^{2}$, this translates into a recording time of $89 \%$ ( $500 \mathrm{~Hz}$ right ear) to $21 \%$ (2 $\mathrm{kHz}$ right ear) of that for conventional singlechannel recording.

The three channels comprised the electrode positions inion, right mastoid, and left mastoid. All three electrode positions were referenced to $\mathrm{Cz}$. Adding a fourth channel $(\mathrm{Pz}-\mathrm{Cz})$ increases the number of participants with significant responses from the $500 \mathrm{~Hz}$ right ear stimulus from 13 to 17. Electrode position F4 and other commonly used positions such as the forehead and right earlobe made significantly less contribution to test efficiency.

Key Words: Amplitude modulation, amplitude modulation following response, auditory steady-state response, EEG, EEG derivation, electrode position, objective audiometry, signal-to-noise ratio, steady-state evoked potential

Abbreviations: $\mathrm{AM}=$ amplitude modulation; $\mathrm{ASSR}=$ auditory steady-state response; $F M=$ frequency modulation; $r_{\mathrm{s}}=$ Spearman rank-order correlation coefficient; SNR = signal-to-noise ratio; $\mathrm{SL}$ = sensation level

\section{Sumario}

Se registraron simultáneamente las Respuestas Auditivas de Estado Estable (ASSR) en 20 adultos despiertos, con audición normal, en diez canales de EEG, para encontrar las derivaciones con las mejores tasas de señal/ruido (SNR). Los estímulos fueron tonos de 0.5 a $2 \mathrm{kHz}$, con un $20 \%$ de modulación de la frecuencia a $20 \mathrm{~dB}$ SL, con un $100 \%$ de modulación de la frecuencia a 90 o $94 \mathrm{~Hz}$, y presentados a un mismo oído, uno a la vez.

\footnotetext{
*Department of Otorhinolaryngology, University Medical Centre Nijmegen, the Netherlands
}

C.S. van der Reijden, Department of Otorhinolaryngology 811, University Medical Centre Nijmegen, P.O. Box 9101, 6500 HB Nijmegen, the Netherlands; Phone: 31-24-3619749; Fax: 31-24-3540251; E-mail: c.vanderreijden@kno.umcn.nl

The Nationaal Revalidatie Fonds (NRF) financially supported part of this study. 
Los registros de las ASSR, utilizando un conjunto de al menos tres canales, mejoraron significativamente el SNR, en un promedio entre el $6 \%(500 \mathrm{~Hz}$ en el oído derecho) al 118\% (2 kHz en el oído derecho), comparado con SNR en los canales convencionales. Asumiendo que el tiempo de registro fue proporcional a $1 /(\mathrm{SNR})^{2}$, esto se traduce en un tiempo de registro de $89 \%$ (500 $\mathrm{Hz}$ en el oído derecho) a $21 \%$ (2 kHz en el oído derecho), comparado con el de los registros convencionales de canal único.

Los tres canales involucraron posiciones de electrodo en el inion, mastoides derecho y mastoides izquierdo. Las tres posiciones del electrodo tuvieron como referencia a $\mathrm{Cz}$. Con la adición de un cuarto canal $(\mathrm{Pz}-\mathrm{Cz})$ se incrementó el número de participantes con respuestas significativas para los estímulos del oído derecho a $500 \mathrm{~Hz}$, de 13 a 17. La posición F4 del electrodo y otras posiciones comúnmente utilizadas, tales como la frente o el lóbulo auricular derecho, contribuyeron significativamente menos a la eficiencia de la prueba

Palabras Clave: Modulación de la amplitud, respuesta de seguimiento en la modulación de la amplitud, respuestas auditivas de estado estable, EEG, derivación de EEG, posición del electrodo, audiometría objetiva, tasa de señalruido, potencial evocado de estado estable

Abreviaturas: $\mathrm{AM}=$ modulación de la amplitud; $\mathrm{ASSR}=$ respuesta auditiva de estado estable; FM = modulación de la frecuencia; $r_{S}=$ coeficiente de correlación de rango-orden de Spearman; SNR = relación señal-ruido

$\mathrm{T}$ he auditory steady-state response (ASSR) is a promising tool to determine hearing thresholds in an objective and frequency-specific manner. It is an electrophysiological response evoked by an amplitude-modulated continuous carrier frequency.

Several authors have suggested that hearing thresholds can be assessed fairly accurately with ASSR measurements (Rance et al, 1995; Lins et al, 1996; Perez-Abalo et al, 2001). Across participants, difference levels between ASSR and behavioral thresholds were found to be about 11--20 dB in the frequency range 1-- $4 \mathrm{kHz}$ and about $11--25 \mathrm{~dB}$ at $500 \mathrm{~Hz}$.

An important factor in the clinical feasibility of the ASSR measurement is the recording time needed to detect responses at stimulus levels close to the hearing threshold. At present, the long recording time of ASSR impedes its clinical use. Aoyagi et al (1999) reported a testing time of about two hours per ear to assess hearing thresholds at four frequencies. John et al (1998) showed that the testing time could be reduced by using multiple amplitude modulated (AM) tones as stimulation, for example, four frequencies in each ear and in both ears simultaneously. However, even with this technique, Mens et al (2001) required a recording time of two hours to test four frequencies per ear in cooperative, awake adult participants with their eyes closed. Rance et al (1995) were able to test five frequencies per ear in both ears in sleeping adults in a much shorter testing time of 30--60 minutes. Although their ASSR thresholds estimated the behavioral thresholds well for a moderate to severe hearing loss, for normal hearing to a mild loss, behavioral thresholds were difficult to estimate especially at carrier frequencies below $1 \mathrm{kHz}$.

Early ASSR studies showed the largest responses at $\mathrm{AM}$ frequencies of around $40 \mathrm{~Hz}$ in awake adults, but this did not apply to young children (Aoyagi et al, 1993). Adults and infants showed another response amplitude maximum at AM frequencies of around $80-100 \mathrm{~Hz}$. In this range of modulation frequencies, the noise level could be reduced considerably if the participant was asleep or sedated, without reducing the response amplitude. Contrastingly, the 40 $\mathrm{Hz}$ response was much more affected by participant state (Cohen et al, 1991). Muscle activity is reduced during sleep or sedation; thus, these states offer important means to optimize signal-to-noise ratios (SNRs). 
However, disadvantages of sedation are the toxic load, the risk of side effects, and the requirement of qualified personnel to administer the medication and monitor the participant. Therefore, there is an urgent need to improve the SNR in awake participants.

Thus far no studies have been reported that describe a systematic search of recording electrode positions with large SNRs. The present study attempted to find these electrode positions.

Cebulla et al (2000) compared SNRs obtained from nonsimultaneous recordings on six EEG channels at a stimulus level of $60 \mathrm{~dB}$ nHL in adult participants with normal hearing. Recordings of responses at the ipsilateral mastoid, the contralateral mastoid, and the neck were compared. All responses were measured with $\mathrm{Cz}$ as reference electrode. The ground electrode was on the forehead, the ipsilateral mastoid, or the contralateral mastoid. The $\mathrm{Cz}$-ipsilateral mastoid derivation with ground on the forehead produced a higher SNR than the other derivations, which was significant in all cases except for the $\mathrm{Cz}$-neck derivation (again with the forehead as ground).

In a previous study, we compared SNRs obtained with an AM in the $90 \mathrm{~Hz}$ range in awake adult participants, using four EEG channels (Van der Reijden et al, 2001). Three of them (nape of the neck, ipsilateral mastoid, and ipsilateral earlobe, all three referenced to $\mathrm{Cz}$ ) are commonly used for ASSR recording, while the fourth, $\mathrm{Cz}$-inion, was a novel one. The latter also showed the best SNR. Recordings were collected successively on different EEG channels due to limitations of the equipment.

Both studies compared a small number of EEG derivations that were recorded nonsimultaneously. This introduced extra within-participant variability between the SNRs of the recordings. To overcome these limitations, multichannel recordings with a larger number of electrodes must be made. An electrode montage with a common reference electrode (see below) then provides the possibility not only to establish SNRs of the measured channels, but also SNRs of calculated channels comprising all possible pairs of electrode positions on the participant's head.

The aim of the present study was to record simultaneous responses in the $90 \mathrm{~Hz}$
AM frequency range while using a large number of EEG channels to establish which derivations produced the best SNRs in awake adults with normal hearing. The EEG was measured using a ten-channel recording with $\mathrm{Cz}$ as the common reference electrode. ${ }^{1}$ Electrode positions were included that have previously been used by other authors (Rees et al, 1986; Cohen et al, 1991; Levi et al, 1993; Rickards et al, 1994; Lins et al, 1995; Aoyagi et al, 1996; Lins et al, 1996; Valdez et al, 1997; Aoyagi et al, 1999; Rance et al, 1999; Cebulla et al, 2000; John and Picton, 2000; Herdman and Stapells, 2001). Electrode position $\mathrm{Pz}$ was added, because a pilot experiment indicated that $\mathrm{Pz}$ produced larger response amplitudes than many of the other electrode positions.

By using a common reference electrode, 45 bipolar EEG derivations that did not involve $\mathrm{Cz}$ could be calculated from the ten (monopolar) recordings referenced to $\mathrm{Cz}$. This was done by subtracting point by point the complete EEGs of two recordings, thus canceling out the contribution of $\mathrm{Cz}$ in each result. In this way 45 calculated EEG derivations were available plus the ten directly measured recordings.

To limit the duration of test sessions, only two stimulus carrier frequencies (500 and $2000 \mathrm{~Hz}$ ) were chosen. It has been reported that the mid-frequencies (1000-2000 $\mathrm{Hz}$ ) produce larger SNRs than the other audiometric frequencies, especially compared to $500 \mathrm{~Hz}$ (John et al, 2001). Therefore, it was even more important for this $500 \mathrm{~Hz}$ carrier frequency to increase the SNR near threshold level. Another reason why the $500 \mathrm{~Hz}$ and the $2000 \mathrm{~Hz}$ carrier frequencies were included was that these are certainly two important frequencies upon which to base hearing aid fitting.

\section{METHOD}

\section{Participants}

Twenty cooperative adult participants with normal hearing (ten women and ten men) were included in this study. All gave informed consent. Age ranged from 22 to 56 years. Hearing thresholds were better than $20 \mathrm{~dB}$ HL from 0.5 to $4 \mathrm{kHz}$, as verified with standard audiometric procedures. Hearing thresholds were also determined for the ASSR 
stimuli. This research received ethical approval from the Local Research Ethical Committee CWOM (submission number 9911-0216).

\section{Auditory Stimuli}

Supra-aural headphones (Beyerdynamic DT48) were used to present the stimuli at a sensation level (SL) of $20 \mathrm{~dB}$, that is, relative to their behavioral thresholds for the same stimuli. Tones of 0.5 and $2 \mathrm{kHz}$ were presented, with $100 \% \mathrm{AM}$ and $20 \%$ frequency modulation (FM) as described by John and Picton (2000). In the left ear, the modulation frequency was $89.844 \mathrm{~Hz}$ (for simplicity abbreviated to $90 \mathrm{~Hz}$ ), while in the right ear it was $93.75 \mathrm{~Hz}(94 \mathrm{~Hz})$. At each measurement only one modulated tone was presented to either the left or the right ear. The FM was applied with a phase of $-90^{\circ}$ at the onset of the stimulus, in order to align the maximum frequency of the stimulus with the maximum amplitude (John and Picton, 2000).

\section{Recording Procedure}

After cleaning the skin with an abrasive gel, disposable electrode discs of $\mathrm{Ag} / \mathrm{AgCl}$ were fixed at 11 positions on the head and one ground electrode on the right wrist (Table 1, Figure 1). EEG paste was used as a conductor, but it also acted as glue to fix the electrodes to the scalp, even in the presence of hair. Ten channel recordings were taken with $\mathrm{Cz}$ as the common reference. EEG signals were measured with software that was functionally similar to the MASTER software (John and
Picton, 2000) but adapted to enable recording of ten channels simultaneously. The EEG was sampled at $4 \mathrm{kHz}$ during a run of 4.4 minutes (256 epochs of 1.024 seconds each) and stored on a hard disc for off-line analysis. The artifact rejection levels for each epoch were +/-20 microvolts. The order of the test frequencies $(0.5$ or $2 \mathrm{kHz})$ and the ear of stimulation were permuted over the participants. Recordings were taken in a quiet room (noise level of less than $23 \mathrm{~dB}$ SPL per octave at $400 \mathrm{~Hz}$ and higher) with dimmed lights. Participants lay supine on a bed and were encouraged to relax the muscles of the jaws as much as possible but were instructed to keep their eyes open and to stay awake during the recordings.

The electrode responses were amplified with a multichannel Nihon Kohden amplifier model MME-3132A/G/K. Signals were bandpass filtered from 20 to $200 \mathrm{~Hz}$ at -12 $\mathrm{dB} /$ octave. We did not use a $50 \mathrm{~Hz}$ notch filter. A gain of 100,000 was used for all channels.

\section{RESULTS}

Point by point differences between the complete EEG signals of all possible combinations of two channels were taken to compute 45 ([10 x 9]/2) bipolar derivations from the ten EEG channels measured with common reference $\mathrm{Cz}$. All 55 derivations (i.e., both measured and calculated) were timeaveraged at intervals of 16 epochs and Fast Fourier Transformed. The frequency resolution was $0.061 \mathrm{~Hz}$. F values were calculated by setting-out the signal power of the response given to a modulation frequency against the average power of 60 frequency bins

Table 1. Recording Electrode Positions Used in This Study

\begin{tabular}{ll}
\hline $\begin{array}{l}\text { Electrode } \\
\text { number }\end{array}$ & $\begin{array}{l}\text { Recording } \\
\text { electrode positions }\end{array}$ \\
\hline 1 & Inion \\
2 & Pz \\
3 & Nape of the neck just below the hairline \\
4 & Fpz (Forehead) \\
5 & Right mastoid \\
6 & Left mastoid \\
7 & F4 \\
8 & F3 \\
9 & Right earlobe \\
10 & Left earlobe \\
11 & Cz \\
\hline
\end{tabular}

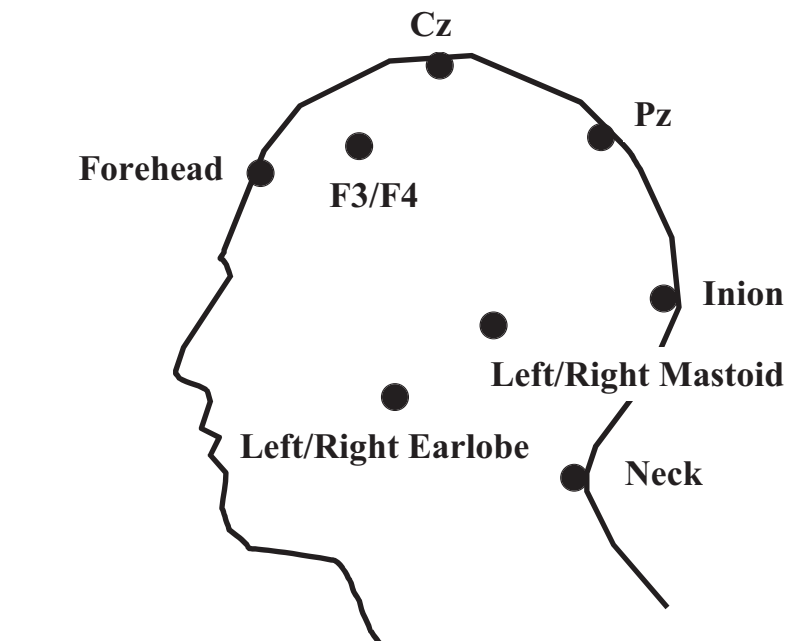

Figure 1. Recording electrode positions used in this study. 


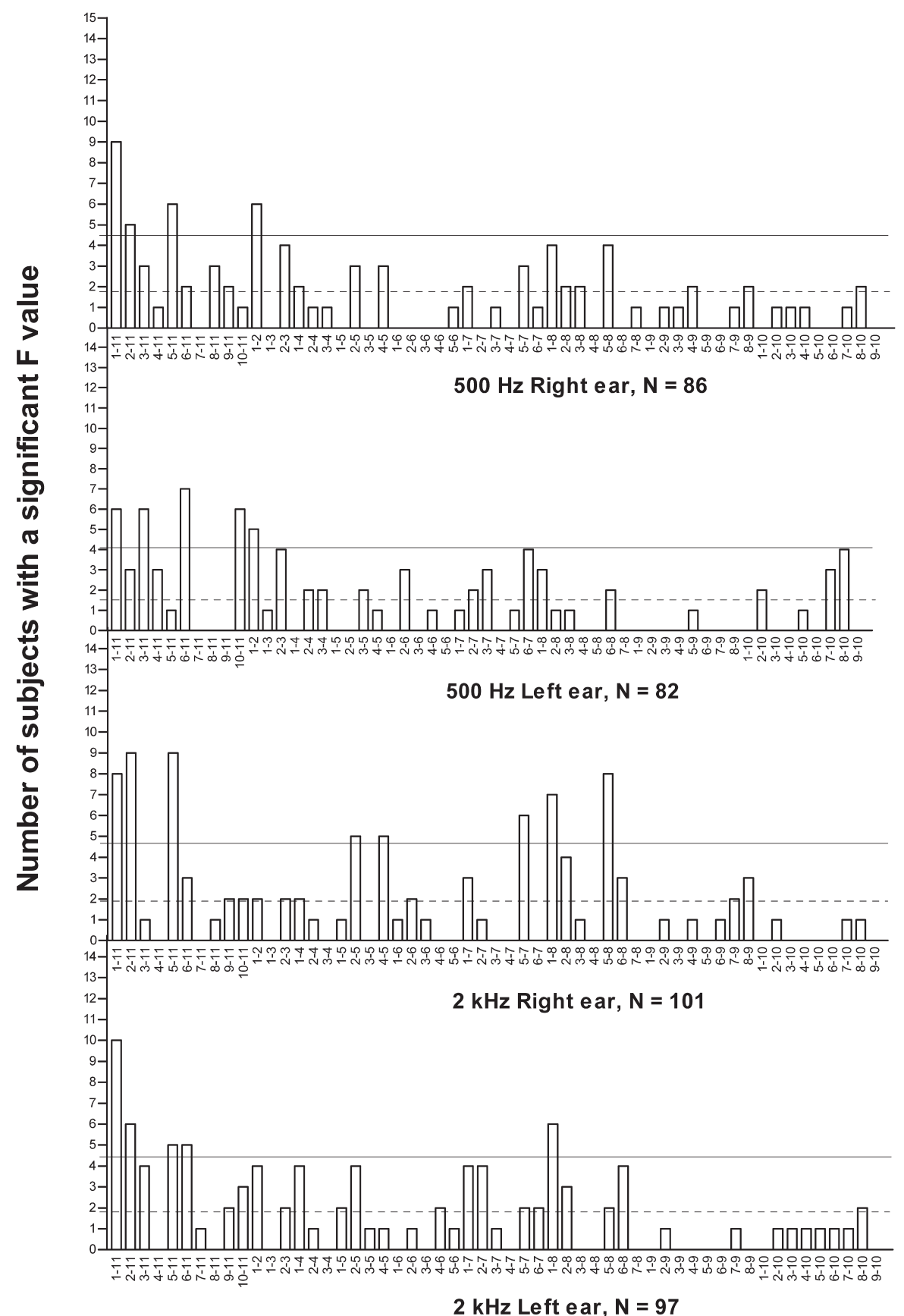

Figure 2. The number of participants who showed a significant response to four combinations of stimulus frequencies (2) and ears was set out against all 55 EEG derivations. The EEG derivations comprise sets of two electrode positions. The electrode numbers in this figure refer to the recording electrode positions as defined in Table 1. Per participant and per stimulus condition, five EEG derivations were identified with the largest SNRs. The number of times a derivation appeared was counted in all participants. The drawn lines indicate $95 \%$ confidence limits. These lines were calculated by Monte Carlo simulations. Derivations that appeared above this level had less than 5\% probability of originating from chance. The dotted line indicates the average chance level. $\mathrm{N}=86,82$, or 97 is the result of participants having less than five significant EEG derivations. $\mathrm{N}=101$ was found because a participant had two derivations with identical significant $F$ values.

\section{EEG derivation}

(considered to be noise) $3.7 \mathrm{~Hz}$ on either side of the modulation frequency. In a one-sided Ftest with 2 and $240(=2 \times[60+60])$ degrees of freedom, a significance level ( $\mathrm{p}$ value) of $2.5 \%(\mathrm{~F}=3.75, \mathrm{SNR}=1.94)$ was used to identify response amplitudes that were significantly above the noise level (Dobie and Wilson, 1996). SNRs were defined as the square root of the $\mathrm{F}$ value (Dobie and Wilson, 1996).
In all 20 participants, a significant response was found to the $2 \mathrm{kHz}$ carrier frequency. At $500 \mathrm{~Hz}$, significant responses were found in 18 participants (left ear) and 19 participants (right ear).

SNRs across all 55 derivations from single measurements did not have a normal distribution within participants (mainly due to outliers) and so did the SNRs of identical derivations between participants. Multivariate 
analysis or another type of parametric analysis would require data with a normal distribution from which outliers (in many cases high SNRs) have been removed. Therefore a nonparametric analysis was used so that equal weights could be given to derivations from each participant regardless of his/her average SNR.

A list was made for each participant of the five derivations with the highest SNR (or less than five if too few were significantly above noise level, or more than five if two derivations had equal SNRs) to create a so-called topfive list per participant. We counted the number of times a particular derivation appeared on a top-five list. Since 20 individuals participated, each derivation could appear a maximum of 20 times per combination of frequencies (two) and ears (two). These counts were summarized into four histograms (Figure 2). They were then subjected to further analysis to identify any high-ranking derivations that were dominant in this participant group and would therefore suffice to record the ASSR efficiently.

We identified derivations that occurred more frequently across participants than could be expected by chance. The average chance level on which a derivation could appear was calculated as 1.82 (the maximum total number of occurrences, 100, divided by 55 ), indicated by the dashed lines in Figure 2. Monte Carlo simulation (Press et al, 1994; Rice, 1995) was performed to find the upper limit of the 95\% confidence interval around the average chance value. Drawn lines in Figure 2 indicate the upper limit. Derivations that occurred less frequently than the upper limit were deleted from the original histograms. The remaining derivations therefore occurred significantly more frequently than could be expected by chance in this participant group. Inspection showed that none of them appeared to all (or most) participants in the top-five list (Figure 2).

To further reduce the set of derivations, we assessed the distribution of SNRs across participants in two stages. First, the (nonparametric) Wilcoxon two-tailed matched pairs test was applied to eliminate any derivations that produced significantly lower SNRs across participants than the others. No derivations could be eliminated at $500 \mathrm{~Hz}$ in either ear. However, at $2 \mathrm{kHz}$ in the right ear, the right mastoid- $\mathrm{Cz}$ derivation produced a significantly better SNR $(\mathrm{p} \leq 0.05)$ than

Table 2. Preferred Set of Derivations That Produced Significant Responses in Many Participants

\begin{tabular}{|c|c|c|c|c|c|c|c|c|}
\hline Frequency & Ear & \multicolumn{5}{|c|}{ Preferred EEG derivations } & $\mathrm{N}_{\mathrm{S}}$ & $\mathrm{N}_{e}$ \\
\hline \multicolumn{9}{|l|}{$r_{s}<0.447$} \\
\hline $2 \mathrm{kHz}$ & left & Inion-Cz & & & & & 17 & 2 \\
\hline $2 \mathrm{kHz}$ & right & Inion-Cz & Right mastoid-Cz & & & & 20 & 3 \\
\hline $500 \mathrm{~Hz}$ & left & Inion-Cz & Left mastoid-Cz & & & & 14 & 3 \\
\hline $500 \mathrm{~Hz}$ & right & Inion-Cz & & & & & 13 & 2 \\
\hline \multicolumn{9}{|l|}{$r_{s}<0.70$} \\
\hline $2 \mathrm{kHz}$ & left & Inion-Cz & & & & & 17 & 2 \\
\hline $2 \mathrm{kHz}$ & right & Inion-Cz & Right mastoid-Cz & $\mathrm{Pz}-\mathrm{Cz}$ & & & 20 & 4 \\
\hline $500 \mathrm{~Hz}$ & left & Inion-Cz & Left mastoid-Cz & Neck-Cz & & & 14 & 4 \\
\hline $500 \mathrm{~Hz}$ & right & Inion-Cz & Inion-Pz & $\mathrm{Pz}-\mathrm{Cz}$ & & & 16 & 4 \\
\hline \multicolumn{9}{|l|}{$r_{s}<0.90$} \\
\hline $2 \mathrm{kHz}$ & left & Inion-Cz & & & & & 17 & 2 \\
\hline $2 \mathrm{kHz}$ & right & Inion-Cz & Right mastoid-Cz & $\mathrm{Pz}-\mathrm{Cz}$ & Inion-F3 & Right mastoid-F3 & 20 & 5 \\
\hline $500 \mathrm{~Hz}$ & left & Inion-Cz & Left mastoid-Cz & Neck-Cz & Inion-Pz & Left earlobe-Cz & 15 & 6 \\
\hline $500 \mathrm{~Hz}$ & right & Inion-Cz & Right mastoid-Cz & $\mathrm{Pz}-\mathrm{Cz}_{n}$ & Inion-Pz & & 17 & 4 \\
\hline
\end{tabular}

Note: Uncorrelated derivations, the number of participants $\left(\mathrm{N}_{\mathrm{S}}\right)$ whose derivations had significant SNRs, and the number of electrodes $\left(\mathrm{N}_{\mathrm{e}}\right)$ involved are displayed for three cutoff values of Spearman correlation coefficients $\left(\mathrm{r}_{\mathrm{S}}\right)$. For $\mathrm{N}=20$ and $\mathrm{p}=0.05, \mathrm{r}_{\mathrm{S}}<0.447$. 
the right mastoid-F4, right mastoid-Pz, and the right mastoid-forehead. So these three were deleted from the final list. At $2 \mathrm{kHz}$ in the left ear, the inion- $\mathrm{Cz}$ derivation produced a significantly better SNR than all the other derivations $(p<0.05)$, so the final list comprised only the inion- $\mathrm{Cz}$ derivation. Second, as the inion- $\mathrm{Cz}$ derivation appeared in the set of selected derivations for all combinations of ears and tones after the Wilcoxon test, redundant EEG derivations were identified by calculating Spearman rank-order correlation coefficients $\left(r_{\mathrm{s}}\right)$ between the SNRs obtained from inion- $\mathrm{Cz}$ and the SNRs of all remaining EEG derivations. Redundant EEG derivations were identified at three cutoff values: $\left(\mathrm{r}_{\mathrm{S}}<\right.$ 0.447 [ $\mathrm{p}=0.05$ in 20 participants], $\mathrm{r}_{\mathrm{S}}<0.70$ $[\mathrm{p}<0.001]$, and $\left.\mathrm{r}_{\mathrm{S}}<0.90[\mathrm{p}<0.0001]\right)$. Derivations with Spearman correlation coefficients exceeding the cutoff value $(0.447$, 0.70 , or 0.90 ) were excluded from the list. The final sets of EEG derivations are summarized at each frequency and in each ear in Table 2. After application of the correlation criterion $\mathrm{r}_{\mathrm{s}}<0.447$, which eliminated the most derivations of the three criteria, four electrodes sufficed to obtain the remaining

Table 3. Improvements of SNRs by the Preferred Derivations from Table 2

\begin{tabular}{|c|c|c|c|c|c|c|}
\hline \multirow[t]{2}{*}{ Frequency Ear } & \multicolumn{6}{|c|}{ Conventional EEG derivations } \\
\hline & Neck-Cz & $\mathrm{Fpz}-\mathrm{Cz}$ & Right mastoid-Cz & Left mastoid-Cz & Right earlobe-Cz & Left earlobe-Cz \\
\hline \multicolumn{7}{|l|}{$r_{s}<0.45$} \\
\hline \multicolumn{7}{|l|}{$2 \mathrm{kHz} \quad$ left } \\
\hline Average ratio* & 1.30 & 1.97 & 1.47 & 1.40 & 1.61 & 1.44 \\
\hline Std Error & 0.10 & 0.18 & 0.15 & 0.13 & 0.13 & 0.13 \\
\hline \multicolumn{7}{|l|}{$2 \mathrm{kHz} \quad$ right } \\
\hline Average ratio & 1.41 & 2.18 & 1.32 & 1.63 & 1.40 & 1.78 \\
\hline Std Error & 0.05 & 0.20 & 0.10 & 0.13 & 0.07 & 0.15 \\
\hline \multicolumn{7}{|l|}{$500 \mathrm{~Hz} \quad$ left } \\
\hline Average ratio & 1.25 & 1.72 & 1.46 & 1.29 & 1.53 & 1.20 \\
\hline Std Error & 0.09 & 0.20 & 0.14 & 0.13 & 0.13 & 0.07 \\
\hline \multicolumn{7}{|l|}{$500 \mathrm{~Hz}$ right } \\
\hline Average ratio & $1.16^{n}$ & 1.54 & $1.06^{n}$ & 1.35 & $1.12^{n}$ & $1.23^{n}$ \\
\hline Std Error & 0.06 & 0.17 & 0.06 & 0.12 & 0.06 & 0.10 \\
\hline \multicolumn{7}{|l|}{$r_{s}<0.90$} \\
\hline \multicolumn{7}{|l|}{$2 \mathrm{kHz} \quad$ left } \\
\hline Average ratio & 1.30 & 1.97 & 1.47 & 1.40 & 1.61 & 1.44 \\
\hline Std Error & 0.10 & 0.18 & 0.15 & 0.13 & 0.13 & 0.13 \\
\hline \multicolumn{7}{|l|}{$2 \mathrm{kHz} \quad$ right } \\
\hline Average ratio & 1.56 & 2.36 & 1.46 & 1.79 & 1.55 & 1.95 \\
\hline Std Error & 0.08 & 0.19 & 0.11 & 0.14 & 0.08 & 0.16 \\
\hline \multicolumn{7}{|l|}{$500 \mathrm{~Hz} \quad$ left } \\
\hline Average ratio & 1.29 & 1.76 & 1.51 & 1.33 & 1.58 & 1.24 \\
\hline Std Error & 0.09 & 0.20 & 0.14 & 0.14 & 0.13 & 0.07 \\
\hline \multicolumn{7}{|l|}{$500 \mathrm{~Hz}$ right } \\
\hline Average ratio & 1.37 & 1.81 & 1.24 & 1.59 & 1.31 & 1.43 \\
\hline Std Error & 0.08 & 0.20 & 0.06 & 0.15 & 0.06 & 0.11 \\
\hline
\end{tabular}

Note: Ratios were calculated between the maximum SNRs produced by the preferred set $\left(\mathrm{SNR}_{\mathrm{Max}}\right)$ in Table 2 and the SNRs produced by the conventional derivations ( $\left.\mathrm{SNR}_{\mathrm{Standard}}\right)$. All ratios were averaged across subjects. All SNRs improved significantly except those denoted by ${ }^{n}$ for $r_{S}<0.45$ in the $500 \mathrm{~Hz}$ right ear condition. *The ratio was calculated as $\mathrm{SNR}_{\mathrm{Max}} / \mathrm{SNR}_{\text {Standard}}$. 
derivations: inion, $\mathrm{Cz}$, left mastoid, and right mastoid. Recordings from other electrodes produced significantly lower SNRs or were highly correlated $\left(r_{\mathrm{s}} \geq 0.447\right)$ with the remaining derivations. Note that the 0.447 criterion resulted in fewer participants for the $500 \mathrm{~Hz}$ right ear condition (13 instead of 17), for which significant SNRs were found compared to the 0.90 criterion. This could be largely avoided by including $\mathrm{Pz}-\mathrm{Cz}$.

The improvement in SNRs in two of the three sets of derivations (Table 2, $\mathrm{r}_{\mathrm{S}}<0.447$ and $r_{\mathrm{S}}<0.90$ ) was quantified against the SNR of each conventional recording. For all participants, frequencies, and ears, ratios were calculated between the highest SNR produced by any of the derivations on the list and that produced by any of the conventional EEG derivations. Average ratios and their standard errors for all these conditions are presented in Table 3. All SNRs improved significantly except for $\mathrm{r}_{\mathrm{S}}<0.47$ in the 500 $\mathrm{Hz}$ right ear condition. This is another reason to include $\mathrm{Pz}-\mathrm{Cz}$ to record responses from this stimulus. If a conventional derivation produced a nonsignificant SNR, instead, a fixed value (SNR 1.91, $\mathrm{p}=0.03 ; \mathrm{F}=3.64$ ), close to the significance level $(p=0.025)$, was substituted in the calculations in order to avoid biasing the comparison in favor of the nonconventional derivations. SNRs from selected derivations ranged from 6 to $118 \%$ above the SNRs obtained from the conventional ones (Table 3). Assuming that the recording time was proportional to $1 /(\mathrm{SNR})^{2}$, this translates into a recording time that was $89 \%$ to $21 \%$ of the time that would be needed for conventional singlechannel recording. In other words, Table 3 shows that clinical application of ASSR might largely benefit from using the selected derivations from Table $2\left(\mathrm{r}_{\mathrm{S}}<0.447\right.$ and $\mathrm{r}_{\mathrm{S}}<$ 0.90 ) instead of the conventional ones because they might reduce recording time between $11 \%$ and $79 \%$.

We also quantified the proportion of the participants that showed a larger SNR in the nonconventional derivations compared to the set of conventional ones. With the $2 \mathrm{kHz}$ stimuli and $\mathrm{r}_{\mathrm{s}}<0.447$ between the nonconventional EEG derivations, 50\% to $100 \%$ of the participants had a larger SNR compared to the range of SNRs of the six conventional recordings in Table 3 . With the $500 \mathrm{~Hz}$ stimuli, this range was between $30 \%$ and $65 \%$ of the participants.

\section{DISCUSSION}

In most ASSR studies, the EEG was recorded on only one channel. The location of the active electrode varied widely between studies. Although most researchers used an electrode at $\mathrm{Cz}$ as a reference, differences in study design make it difficult to compare the efficiency of the active electrode positions. In the present study, a larger number of electrode positions were tested including most of the positions used by other authors to establish whether alternative positions, or an increased number of positions, could improve the SNR in individual participants. Within-participant variability was minimized by recording all the channels simultaneously.

The results indicated that a small set of three derivations $(\mathrm{Cz}$-inion combined with the right mastoid-Cz and left mastoid-Cz) yielded the best SNRs in a larger number of participants than would be expected if all derivations were equally efficient. Compared to any of the conventional single-channel derivations, this set of derivations led to improvement in the SNR in $30 \%$ to $65 \%$ of the participants at $500 \mathrm{~Hz}$ and in $50 \%$ to $100 \%$ at $2 \mathrm{kHz}$. Although detecting responses from a $500 \mathrm{~Hz}$ stimulus in the right ear could be improved further by adding $\mathrm{Pz}-\mathrm{Cz}$ to the set of three derivations, improvements were smaller for the $500 \mathrm{~Hz}$ stimulus than for the $2 \mathrm{kHz}$ stimulus mainly because more participants had nonsignificant $\mathrm{F}$ values at $500 \mathrm{~Hz}$ than at $2 \mathrm{kHz}$. In other words, even with an optimized set of multiple electrode positions, recording the ASSR at $500 \mathrm{~Hz}$ will be more difficult than at $2 \mathrm{kHz}$ and therefore will require a longer time to reach threshold in clinical testing.

Thus, a four-channel setup (inion, right mastoid, left mastoid, and $\mathrm{Pz}$ ) with $\mathrm{Cz}$ as a common reference would suffice to record the EEG. If circumstances prohibit recording on four channels, it seems advisable to use the inion and $\mathrm{Cz}$, because these positions were found to be important for all conditions and, if possible, to add the left and right mastoid positions.

In the first step of our analysis, derivations that produced a significant response were identified in each recording using the $\mathrm{F}$ test and a $\mathrm{p}$ value of $2.5 \%$. Therefore, in the worst case, that is, no response present, on average only 1.4 out of 55 derivations would have produced a false 
positive result and entered our top five by chance. This small number of false positives would then have been removed by the Monte Carlo procedure, because only those derivations were selected that occurred in a larger number $(>4)$ than the upper limit of the 95\% confidence interval across participants. In addition, most $F$ values were much larger than the critical significance $(\mathrm{F}=3.75, \mathrm{p}=$ $0.025)$ level, which reduced even further the number of false positives in the final analysis. A more serious issue in clinical testing, if multiple channels are used, is that the number of false positives will increase if the statistical criterion is not raised. If three channels are used, we suggest employing a $1 \%$ criterion ( $F$ $=4.69, \mathrm{SNR}=2.17$ ) per derivation, to keep the overall false positive rate well below $5 \%$

Note that the analysis is valid even if the EEG activity between each of the 55 derivations is not independent. For example, in the extreme case of complete correlation, all the derivations would appear on average equally often on the top five lists, and the Monte Carlo method would not identify any dominant derivations in this group of participants, which clearly was not the case.

Näätänen and Picton (1987) have already reported the importance of $\mathrm{Cz}$ reference position for recording responses evoked by auditory stimuli in adults. In the present study, several combinations that included $\mathrm{Cz}$ played important and complementary roles in detecting large $\mathrm{F}$ values: inion- $\mathrm{Cz}$ was found in the final set at all frequencies and in ears. This confirms our findings in an earlier study in which nonsimultaneous recordings were made from several positions (Van der Reijden et al, 2001).

Only one other study compared different EEG derivations (six) recorded consecutively (Cebulla et al, 2000). Although there were some differences in study design $(1 \mathrm{kHz}$ carrier, participants were asleep most of the time, the inion- $\mathrm{Cz}$ derivation was not included), the authors reported the highest SNR on the ipsilateral mastoid as opposed to the contralateral side (with a ground electrode on the forehead), which is in agreement with the present results.

The preferred sets of EEG derivations in Table 2 suggest that the source of 90 and 94 $\mathrm{Hz}$ activity is located below the parietaloccipital area, close to the brainstem. As has been reviewed by Picton et al (2003), this is also suggested by other authors based on short apparent latencies that they found in the $80-100 \mathrm{~Hz}$ modulation frequency range as compared to the longer apparent latencies at the $40 \mathrm{~Hz}$ modulation frequency.

Large differences in $\mathrm{F}$ values (ranging from 3.75 to 121) were found between participants using the same EEG derivations. These differences may reflect individual differences in amplitude, source location, or orientation of the neural dipole generators. Pantev et al (1996) performed a MEG study on the tonotopic organization of the sources of human auditory steady-state responses in eight women and nine men. Their stimuli comprised $500 \mathrm{~Hz}$ and $2 \mathrm{kHz}$ carrier frequencies, which were amplitude modulated at $40 \mathrm{~Hz}$. Their dipole source analysis, based on a single moving equivalent current dipole model, estimated a between-participant variability of about $1 \mathrm{~cm}$ around the mean dipole location. This may have an effect on the magnetic field around the head. At least one other factor needs to be considered, namely the dimensions of the skull and scalp. Cuffin (1993) modeled the effects of local variations in skull and scalp thickness on the localization accuracy of a putative source using EEG and MEG. The model indicated that EEG and MEG recordings could be greatly influenced not only by different locations ( 1 or $2 \mathrm{~cm}$ depth) of a dipole but also by variations (+/$0.4 \mathrm{~cm}$ ) in skull and scalp thickness. EEG potentials varied by about $20 \%$ due to realistic variations in skull and scalp thickness, and by about $20 \%$ due to a $1 \mathrm{~cm}$ shift in the dipole location. Calculations on MEGs showed similar behavior. Therefore, variations in skull and scalp thickness can have definite impact on intra- and interindividual variability in auditory evoked potentials. Multichannel recordings from optimized electrode positions instead of a single-channel approach may help to deal with this variability.

In summary, recording ASSR from the EEG channels with high SNRs may help to reduce recording time in the clinic and to achieve more accurate frequency specific hearing threshold estimates in adults. As noted earlier, skull and scalp thickness may play an important role in detection of evoked potentials. Therefore, the EEG channels with high SNRs in adults may not be the same as those in infants, since their skull is still developing. Further study is needed to optimize the recording of ASSR in infants. 
Acknowledgments. The authors thank Professor Dick Stegeman, Leo Haegens, Yvonne van de Bogaard, and colleagues at the Department of Clinical Neurophysiology for their valuable support. We also thank the three anonymous reviewers.

\section{NOTES}

1. Here the term "reference" is used to indicate that all potentials were recorded relative to $\mathrm{Cz}$.

\section{REFERENCES}

Aoyagi M, Kiren T, Kim Y, Suzuki Y, Fuse T, Koike Y. (1993) Optimal modulation frequency for amplitude-modulation following response in young children during sleep. Hear Res 65:253-261.

Aoyagi M, Suzuki Y, Yokota M, Furuse H, Watanabe T, Ito T. (1999) Reliability of $80-\mathrm{Hz}$ amplitude-modulation-following response detected by phase coherence. Audiol Neurootol 4:28-37.

Aoyagi M, Yamazaki Y, Yokota M, Fuse T, Suzuki Y, Itoh S, Watanabe T. (1996) Frequency specificity of 80-Hz amplitude-modulation following response. Acta Otolaryngol (Stockh) Suppl 522:6-10.

Cebulla M, Stürzebecher E, Pschirrer U. (2000) Registrierung der AMFR-Einfluss von Elektrodenposition und Modulationsfrequenz. [Recording the Amplitude Modulation Following Response-influence of electrode position and modulation frequency.] $Z$ Audiol 39:78-85.

Cohen LT, Rickards FW, Clark GM. (1991) A comparison of steady-state evoked potentials to modulated tones in awake and sleeping humans. J Acoust Soc Am 90:2467-2479.

Cuffin BN. (1993) Effects of local variations in skull and scalp thickness on EEG's and MEG's. IEEE Trans Biomed Eng 40:42-48.

Dobie RA, Wilson MJ. (1996) A comparison of t test, $\mathrm{F}$ test, and coherence methods of detecting steadystate auditory-evoked potentials, distortion-product otoacoustic emissions, or other sinuoids. JAcoust Soc Am 100:2236-2246.

Herdman AT, Stapells DR. (2001) Thresholds determined using the monotic and dichotic multiple auditory steady-state response technique in normalhearing subjects. Scand Audiol 30:41-49.

John MS, Dimitrijevic A, Van Roon P, Picton TW. (2001) Multiple auditory steady-state responses to AM and FM stimuli. Audiol Neurootol 6:12-27.

John MS, Lins OG, Boucher, Picton TW. (1998) Multiple auditory steady-state responses (MASTER): stimulus and recording parameters. Audiology 37:59-82.

John MS, Picton TW. (2000) MASTER: a Windows program for recording multiple auditory steady-state responses. Comput Methods Programs Biomed 61:125-150.

Levi EC, Folsom RC, Dobie RA. (1993) Amplitudemodulation following response (AMFR): effects of modulation rate, carrier frequency, age and state. Hear Res 68:42-52.

Lins OG, Picton TW, Boucher BL, Durieux-Smith A, Champagne SC, Moran LM, Perez-Abalo MC, Martin V, Savio G. (1996) Frequency-specific audiometry using steady-state responses. Ear Hear 1796:81-96.

Lins OG, Picton PE, Picton TW. (1995) Auditory steady-state responses to tones amplitude-modulated at 80-110 Hz. J Acoust Soc Am 97:3051-3063.

Mens LHM, Van der Reijden CS, Wouters J, Gelders E, Snik A. (2001) The amplitude modulation following response: results with the MASTER system using six different EEG derivations. Abstract. In: 2nd International Symposium and Workshop on Objective Measures in Cochlear Implantation. Lyon, France, 67.

Näätänen R, Picton TW. (1987) The N1 wave of the human electric and magnetic response to sound: a review and an analysis of the component structure. Psychophysiology 24:375-425.

Pantev C, Roberts LE, Elbert T, Roß B, Wienbruch C. (1996) Tonotopic organization of the sources of human auditory steady-state responses. Hear Res 101:62-74.

Perez-Abalo MC, Savio G, Torres A, Martín V, Rodríguez E, Galán L. (2001) Steady-state responses to multiple amplitude modulated tones: an optimized method to test frequency-specific thresholds in hearing-impaired children and normal-hearing subjects. Ear Hear 22:200-211.

Picton TW, John MS, Dimitrijevic A, Purcell D. (2003) Human auditory steady-state responses. Int J Audiol 42:177-219.

Press WH, Flannery BP, Teukolsky SA, Vetterling WT. (1994) Confidence limits by Monte Carlo simulation. In: Press WH, Flannery BP, Teukolsky SA, Vetterling WT, eds. Numerical Recipes in Pascal. Cambridge: Cambridge University Press, 582-584.

Rance G, Beer DE, Cone-Wesson B, Shepherd RK, Dowell RC, King AM, Rickards FW, Clark GM. (1999) Clinical findings for a group of infants and young children with auditory neuropathy. Ear Hear 20:238-252.

Rance G, Rickards FW, Cohen LT, De Vidi S, Clark GM. (1995) The automated prediction of hearing thresholds in sleeping subjects using auditory steadystate evoked potentials. Ear Hear 16:499-507.

Rees A, Green GGR, Kay RH. (1986) Steady-state evoked responses to sinusoidally amplitude-modulated sounds recorded in man. Hear Res 23:123-133.

Rice JA. (1995) Mathematical Statistics and Data Analysis. 2nd ed. Belmont, CA: Duxbury Press, 72-73.

Rickards FW, Tan LE, Cohen LT, Wilson OJ, Drew JH, Clark GM. (1994) Auditory steady-state evoked potential in newborns. Br J Audiol 28:327-337.

Valdez JL, Perez-Abalo MC, Martin V, Savio G, Sierra C, Rodriguez E, Lins O. (1997) Comparison of statistical indicators for the automatic detection of 80 $\mathrm{Hz}$ auditory steady-state responses. Ear Hear 18:420-429.

van der Reijden CS, Mens LHM, Snik AFM. (2001) Comparing signal-to-noise ratios of amplitude modulation following responses from four EEG derivations 